\title{
The Relationship between Iranian EFL Learners' Critical Thinking and Reading Comprehension Performance in Journalistic Texts
}

\author{
Mohammad Taghi Hassani \\ Islamic Azad University, Takestan, Iran; \\ Imam Hossein University, Tehran, Iran \\ Ramin Rahmany \\ Islamic Azad University, Takestan, Iran \\ Mohammad Babaei \\ Islamic Azad University, Takestan, Iran
}

\begin{abstract}
The purpose of the present study was to investigate the relationship between critical thinking and journal text reading comprehension in Iranian EFL learners. 90 students of English translation at Abhar Payame Noor University participated in this study. After running the proficiency test, 62 students were selected as a homogenous group for this project. One questionnaire of critical thinking and one journalistic test for measuring their reading comprehension proficiency were administered to find out the relationship between critical thinking and reading comprehension of journalistic text. The Persian version of questionnaire (Honey, 2004) was given to the subjects. After the questionnaire, journalistic reading test consisting of four passages and 40 items was given to the subjects. Strong correlation found between the two variables through using Pearson Product Moment Correlation. The findings of present study can have theoretical and practical implications for improving EFL learners' ability in reading journalistic text.
\end{abstract}

Index Terms — reading comprehension, critical thinking, critical reading, journalistic text

\section{INTRODUCTION}

Critical thinking is an important every day activity. Every time we have to make a decision, the process we go through involves critical thinking. Nowadays, critical thinking is one of the major concepts under consideration in education. Critical thinking has been mostly used for first language education in the United States, but today its role in second and foreign language learning and teaching is of great importance (Atkinson, 1997).

Critical thinking is important in education; Lioyd and Bahr (1995) believe that successful learners are those who are able to think about reasons in a logical manner.

Many researchers believe that there is a necessity for everyone to become better critical thinker. They have implicit hope that enriched critical thinking has a general humanized effect among all social groups and different classes of the society. Therefore, for all students and teachers it is necessary to learn critical thinking for their own educational development and understand its role in their future life.

According to Facione (1990), "we understand critical thinking to be purposeful, self regulatory judgment which results in interpretation of the evidential, conceptual, methodological, or contextual considerations upon which that judgment is based. Critical thinking is essential as a tool of inquiry. As such, critical thinking is a liberating force in education and a powerful resource in one's personal and civic life" (p.3).

There are many reasons to support that critical thinking in society is as important as educational and professional contents. Moon (2003) states that critical thinking is the actual meaning of being a developed person living a democratic society; or moving toward democratic societies. On the other hand, human beings by critical thinking power can write their words and sentences directly or indirectly. Journalists can also write and tell their ideas explicitly or implicitly.

Therefore, people find and understand the meaning of their writing by analyzing and comprehending the text. Cody (1997) reported that even the students in advance level read the text, analyze discourse and use the techniques of thinking critically. Recent theories have suggested that the ability to think critically is one of the most important devices for processing information and absorbing knowledge.

Hall (1989) stated that with emergence of the cognitive approach, focus is on meaning, context and thinking. For comprehending journalistic text and understanding the gist of the text, the reader needs to control her/his thinking to process information to judge about data and decide to analyse and answer to questions. Also currently, reading has 
centered on psychological perspective in which the reader utilizes her or his background knowledge, prior knowledge of language structure, context and cultural back ground for making a sense and interpreting a text (Hall, 1989)

Also discourse is another important feature of any text. Gee (1996) stated that most people introduce language which is used in the text or speech as a means of communicating information but language can shape the culture and social activities of humans within social groups.

Although the relationship between critical thinking and many different fields is studied in many academic works, observing the effect of critical thinking on journalistic text is yet new.

\section{A. Critical Thinking}

In the information age, people must ask question and find the ways of solving problems. A person who thinks critically can ask appropriate questions, gather relevant information, efficiently and creatively sort through this information, reason logically from this information, and come to reliable and trust worthy conclusion about the world that enable him to live and act successfully in it (Center for CT, 1996a).

According to Atkinson (1997) critical thinking is one of the major concepts under consideration in education. Critical thinking has been mostly used for first language education in the United States, but today its role in second and foreign language learning is of great importance. Moon (2008) states that critical thinking and its relationship to the educational process has become a central issue and it is time to explore the term. She believes that since critical thinking is a process which is involved in any research activity; it can be considered as a principal concept in education, especially at higher levels. Critical thinking is also important in relation to other disciplines (e.g. management or social sciences) or professions (e.g. medicine or social work) or master levels and undergraduate levels. That is to say, critical thinking can be considered as an important facilitator of what students are expected to achieve at the end of a level in higher education program. For instance, at the higher Educational levels students should have critical evaluation abilities, provide logical and reliable suggestions, and investigate contradictory information; all these capabilities require a welldeveloped way of thinking critically.

There are many reasons that could be given here to support that critical thinking in society is as important as in educational and professional contexts. Moon (2003) states that critical thinking is the actual meaning of being a developed person living in a democratic society or moving toward democratic societies.

Many researchers approve remarkable effects of critical thinking, but they give no unique definition while describing the term. The following are some examples of attempts to define critical thinking:

"Critical thinking is the ability to analyze facts, generate and organize ideas, defend opinions, draw inferences, evaluate arguments and solve problems" (Chance, 1986, p.6).

"Critical thinking is a way of reading that demands adequate support of one's beliefs and an unwillingness to be persuaded unless support is forth coming" (Tama, 1989, p.64).

"Critical thinking is reasonable reflective thinking focused on deciding what to believe or do" (Ennis, 1992.p27).

"Critical thinking is the organized cognitive process we use to carefully examine our thinking and thinking of others in order to clarify and improve our thinking" (Chaffee, 1999, p.5).

"Critical thinking is the ability of a person to think critically about one's own thinking known as "meta-cognition" (Paul, 2004).

"Critical thinking is in short, self-directed, thinking" (Paul, 2008)

Critical thinking is the best understood as the ability of thinkers to take charge of their own thinking. This requires that they develop sound critical and standards for analyzing and assessing their own thinking and routinely use those criteria and standards to improve its quality (Paul and Elder, 1997).

\section{B. Reading Comprehension}

Although there have been many definitions of reading, it is not easy to define it in a single sentence. For example Chastain (1988) defines reading as a process involving the activation of relevant knowledge and related language skills to accomplish an exchange of information from one person to another. Grabe and Stoller (2002) define reading as the ability to draw meaning from the printed page and interpret this information appropriately.

According to Nunan (1999), people in reading have different strategies. For example reading a label on a bottle of water does not require the same strategies as reading academic texts. Chastain (1998) states the goal of reading as getting the meaning or recreating the writer's meaning. He believes that reading to improve pronunciation or practice grammatical forms does not constitute reading. In his view comprehension of what learners read is the goal of reading.

\section{Critical Thinking and Reading}

Bala subramaiam (1991) defines deep comprehension as the ability to recognize, organize, and articulate the central idea of text without conflating them with peripheral details. Kurland (2000) claims that comprehension requires higherorder thinking. He states that reading actually a problem solving process requires cognition. According to Kurland (2002), "We do not simply read the words; we read ideas, thoughts that spring from the relationships of various assertions". (p.2).To understands text deeply, it is necessary to construct meaning through connection and interpretation of the author's ideas. 
Byrnes (2001) believes that good readers can recognize word automatically which enables the individual to focus on higher order thinking by utilizing sentence integration and making semantic connections. Secondly, good readers quickly recognize words. Speed is important because readers need to operate on information in working memory before it dissipates (Byrnes, 2001). The third characteristic of good reader is their ability to record words in to phonological representations. The phonological skills help the individual to create a code and stable pathway of working memory to effectively access word meanings.

\section{METHOD}

Intended plan of this study is to evaluate the relationship between critical thinking and press reading comprehension in Iranian English language learners. For this purpose a test of reading comprehension and a questionnaire of critical thinking were administered and the results were obtained.

\section{A. Participants}

In this study, 62 male and female students whose age - range was from 20-37 were selected out of 90 students, majoring in English translation from Abhar Payame Noor University.

Sex and age were not assumed as moderator variables, so their effects on the process of the study were not considered. The reason for selecting senior English translation students was that this study's participants must have enough general English knowledge to be able to read and answer a critical thinking questionnaire as well as reading comprehension tests.

\section{B. Instrument}

The materials used for this study include a proficiency test, a critical thinking questionnaire, and three press reading comprehension tests to measure impact of critical thinking on press reading comprehension.

A TOEFL test (2000) used to minimize individual differences among the participants and ensure the close homogeneity of them. It includes 50 structure tests and 50 reading comprehension test. Listening test was not the focus of this study and was deliberately omitted. As a result, the subjects whose score were between one standard deviation above and below the mean were selected as the participants of this study. Consequently, 62 students were chosen for this research.

A Critical thinking questionnaire by Peter Honey (2004, as cited in Naeini, 2005) which contained 30 closed questions was used to evaluate Critical thinking skills. According to Naeini (2005), the Persian version of the questionnaire was studied by some professors at Tehran Azad University and they modified it. The reliability of questionnaire was 0.86 and considered acceptable.

A press reading comprehension test was developed by the researchers to measure students' performance on press reading comprehension. At first, four reading passages from five passages from South China Morning post were selected. Then the researchers put 16 multiple choice questions at the end of the every passage.

Next, the tests were piloted on 20 students majoring in English translations. After getting feedbacks from the students and after adding and deleting the number of questions for each passage the appropriate items were prepared to using for this research.

\section{Procedure}

To obtain the answer to the research question of this study, at first, TOEFL test was administered among 90 English translation students of Abhar Payame Noor in order to homogenize the sample group. After analyzing the scores 28 students whose scores were beyond one standard deviation above and below the mean were excluded from the study. Four journalistic reading comprehension passages with their questions and a critical thinking questionnaire were given to the rest of the participants in two sessions. At the first session, the critical thinking questionnaire was given to them; this questionnaire reflected and specified their inferences, evaluations, and inductive / dedicative reasoning. Participants completed their questionnaire in the classroom and delivered them. In the next session, news story alongside its questions was given to the participants which included four passages and it took 70 minutes for students to answer the questions.

\section{RESULTS}

To ensure the homogeneity of the participants, the researcher administered TOEFL to 90 participants. Those students whose TOEFL scores were between one standard deviation above and one standard deviation below the mean of 63.69 were selected as homogeneous participants of this study. Therefore, 62 students whose score were between 53 and 64 were chosen. Table 1 indicates the statistical data of participants' scores on critical thinking questionnaire.

TABLE 1.

DESCRIPTIVE STATISTICS FOR CRITICAL THINKING QUESTIONNAIRE

\begin{tabular}{|l|l|l|l|l|l|l|l|l|l|}
\hline & $\mathrm{N}$ & Range & Min. & Max. & Mean & Mode & Median & SD & Variance \\
\hline Critical Thinking & 62 & 95 & 46 & 141 & 90.69 & $95 \mathrm{a}$ & 91.00 & 24.584 & 604.380 \\
\hline
\end{tabular}


The descriptive statistics of participants' scores on journal reading comprehension are set forth in Table 2.

TABLE 2.

DESCRIPTIVE STATISTICS FOR JOURNAL READING COMPREHENSION

\begin{tabular}{|l|l|l|l|l|l|l|l|l|l|}
\hline Parameter & $\mathrm{N}$ & Range & Min. & Max. & Mean & Mode & Median & SD & Variance \\
\hline $\begin{array}{l}\text { Journal Reading } \\
\text { Comprehension }\end{array}$ & 62 & 18 & 20 & 38 & 28.31 & 29 & 28.50 & 4.167 & 17.36 \\
\hline
\end{tabular}

According to Table 2, 62 participants took journal reading comprehension test with a mean, mode, and median of $28.31,29$, and 28.50 respectively that are very near to one another. Thus we can claim that the scores of journal reading comprehension are normally distributed. Moreover, range is 18 and variance is 17.36 .

Figure 1 represents statistical information of the descriptive statistics together with frequency of participants 'scores on journal reading comprehension test. The minimum score is 20 with the frequency of two students, and the maximum score is 38 with the same frequency of one student.

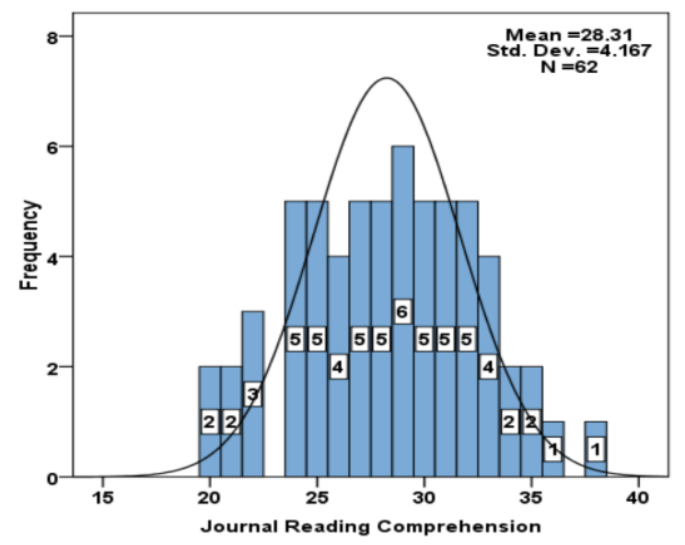

Figure 1. Distributions of Participants' Results on Journal Reading

\section{Test of Normality}

In order to see whether participants' critical thinking and journal reading comprehension scores were normally distributed, Kolmogorov-Smirnov Normality Test was applied. The results of this analysis are represented in Table 3.

TABLE 3.

ONE-SAMPLE KOLMOGOROV-SMIRNOV TEST OF NORMALITY FOR CRITICAL THINKING AND JOURNAL READING COMPREHENSION SCORES

\begin{tabular}{|c|c|c|c|}
\hline \multicolumn{2}{|l|}{ Parameters } & Critical Thinking & $\begin{array}{l}\text { Journal Reading } \\
\text { Comprehension }\end{array}$ \\
\hline \multirow{3}{*}{ Normal Parameters ${ }^{a,, b}$} & \multirow{8}{*}{$\begin{array}{l}\text { N Mean } \\
\text { Std. Deviation Absolute Positive } \\
\text { Negative } \\
\text { Kolmogorov-Smirnov Z } \\
\text { Asymp. Sig. (2-tailed) }\end{array}$} & 62 & 62 \\
\hline & & 90.69 & 28.31 \\
\hline & & 24.584 & 4.167 \\
\hline \multirow[t]{5}{*}{ Most Extreme Differences } & & .071 & .066 \\
\hline & & .071 & .060 \\
\hline & & -.037 & -.066 \\
\hline & & .558 & .520 \\
\hline & & .884 & .919 \\
\hline
\end{tabular}

The results in Table 3 shows that participants' both critical thinking and journal reading comprehension scores are normally distributed because Sig. for critical thinking and journal reading comprehension were not significant and they were .88 and .92 respectively ( $\mathrm{Sig}>.05)$.

The relationship between critical thinking and journal reading comprehension was investigated using Pearson product-moment correlation coefficient. The results of this correlation analysis are laid in Table 4.

TABLE 4.

CORRELATION BETWEEN PARTICIPANTS' CRITICAL THINKING AND JOURNAL READING COMPREHENSION SCORES

\begin{tabular}{|c|c|c|}
\hline & Critical Thinking & $\begin{array}{l}\text { Journal Reading } \\
\text { Comprehension }\end{array}$ \\
\hline \multirow{3}{*}{$\begin{array}{l}\text { Pearson Correlation } \\
\text { Critical Thinking } \\
\text { Sig. (2-tailed) N }\end{array}$} & 1 & $.556^{* *}$ \\
\hline & & .000 \\
\hline & 62 & 62 \\
\hline \multirow{3}{*}{$\begin{array}{l}\text { Pearson Correlation Journal Reading } \\
\text { ComprehensionSig. (2-tailed) }\end{array}$} & $.556^{* *}$ & 1 \\
\hline & .000 & \\
\hline & 62 & 62 \\
\hline
\end{tabular}

**. Correlation is significant at the 0.01 level $(\mathrm{Sig}<\alpha)$. 
A quick look at Table 4 reveals that a dramatic positive correlation coefficient $(\mathrm{r}=.556, \mathrm{p}=.0)$ can be observed between participants' critical thinking and journal reading comprehension scores. This amount of correlation is significant since the level of significance is .000 which is less than that of the chosen significance level, .05 $(\operatorname{Sig}<\alpha)$. In addition, the correlation coefficient obtained of this study (.55) exceeds critical values of Pearson productmoment correlation coefficient (.25) with the assigned degree of freedom (60). Therefore, the null hypothesis of this study which states that "There is no significant correlation between EFLLearners' critical thinking and journal reading comprehension score" is rejected. Accordingly, with $95 \%$ confidence, we can safely claim that there exists a statistically significant positive correlation between Iranian EFL learners' critical thinking and journal Reading comprehension scores.

\section{DISCUSSION}

The results of this study show that .55 correlations could be observed between critical thinking and journal reading comprehension variables. Different authors interpret the value of correlation differently; however, Cohen (1998, pp. 79-81) suggests some guidelines. These guidelines are mentioned in Table 5.

TABLE 5 .

\begin{tabular}{|l|} 
GUIDELINES FOR INTERPRETING THE VALUE OF CORRELATION \\
\hline Small \\
Medium
\end{tabular}

According to this guideline, the correlation between.10 to .29 is considered small, .30 to .49 medium, and .50 to 1.0 large. Therefore, based on Cohen's guideline, the relationship between these two variables in this study is large.

The findings of the present study coincide with Cody's (1997) opinion that even the students in advance level read the text, discourse analysis and the techniques of thinking critically. Likewise, recent theories have suggested that ability to think critically is one of the most important devices for processing information and absorbing knowledge.

In addition, the findings of this study are in line with Moon's (2008) belief that critical thinking and its relationship to the educational process has become a central issue and it is time to explore the term. She believes that critical thinking is a process which is involved in any research activity.

\section{CONCLUSION}

The finding of this study revealed that students who are critical thinkers have better performance in reading journalistic texts. It can be concluded that teaching critical thinking skills in university is another point in favor of the fact that teachers can closely monitor the stages of students' progress in thinking and help them when they need. Students should consider critical thinking an important skill in their lives because it can change their view point toward everything. In the domain of education, it encourages students to look everything carefully, concisely, and hesitantly and search for available information. It helps them to seek reliable knowledge, be responsible for their learning and their life, and as a creative person have significant effect on the future of their society.

According to the result of this study, teachers should pay more attention to the effect of critical thinking on the learning process. Syllabus designers and coursebook writers should consider critical thinking as an effective element in their program. To develop teachers' ability for teaching critical thinking, school must commit significant time and resources to professional development. Thus, using critical thinking skills is fruitful in both everyday life and academic success.

\section{REFERENCES}

[1] Atichon, D. (1997). A critical approach to critical thinking in TESOL, TESOL Quarterly, 31, 71-94

[2] Balasubramaniam, A. (1999). Comprehension critical thinking\& creative thinking: A tricriterical approach to student assessment. In Washburn, D.K (2006). Analysis of reading comprehension and critical thinking process achievement based on neurocognitive research, doctorial dissertation. Liberty University. Retrieved August $13, \quad 2009$ from:www.idigtalcommons.liberty.edu/doctoral.

[3] Byrnes, j. p. (2001).Cognitive and development and learning in instructional context. Boston. MA: Allyn\& Bacon

[4] Carr, K, S. (1990). How can we teach critical thinking? ERIC Clearing house on Elementary and Early Childhood Education: (online), ED 326304. Retrieved April 28, 2012 from htt://www.edpsycinteractive.org/filescrithink.html.

[5] Chaffee, J. (1999). Critical Thinking, Thoughtful Writing. Boston: Houghton Mifflin Company.

[6] Chance, p. (1986). Thinking in the classroom: A survey of programs. USA: Mishavaku

[7] Chastain, K. (1998). Developing second - language skills: theory and practice. University of Virginia: H.B.J. Publishers.

[8] Cody, J. (1997). A psycholinguistic model of the ESL reader. Reading in a second language Rowely, MA: Newbury House.

[9] Ennis, R.H. (1992). The degree to which critical thinking is subject specific: Clarification and needed research. In S.P. Norries (Ed), The geralizability of critical thinking. (Pp.21-37) New York: Teachers College Press, Columbia University.

[10] Facione, P.A. (1990). Critical thinking: A statement of expert consensus recommendation. American Philosophical Association.

[11] Fairclough, N. (1995). Discourse analysis. Longman: New York. 
[12] Falarady, T. (1994). A guide to reading comprehension and critical thinking. Denver, Clorado, Denver Publish School. Retrieved June 3, 2008 from www.eric.ed.gov.

[13] Foundation for Critical Thinking. (1999). Critical Thinking: Basic Theory and Instructional Structures. Sacramento, California.

[14] Grabe,W. (1991), Current development in second language reading research. TESOL Quarterly, 25,375-406.

[15] Grabe,W. \& Stoller, F.L. (2002). Teaching and researching reading. Harlow: Pearson Education.

[16] Honey, P. (2002). Critical thinking questionnaire. Retrieved Oct, 2004 from http://www.Peter Honey.com

[17] Knott, D. (2005). Critical reading toward critical writing, Toronto University. Retrieved April 13, 2008 from http://www.writing.utoronto.ca/advice/reading-and researching/critical-reading.

[18] Kurland, D.J. (2000). Critical reading V. critical thinking, In how language really works: The fundamentals of critical reading and effective writing. Retrieved 23 march 2009 from: www.criticalreading.com

[19] Mc Gee, L (2008). Travesing the lexical cohesion minefield. ELT Journal.vol.16/3.

[20] Moon, J. (2008). Critical Thinking of Theory and Practice. Library of Congress: UK.

[21] Naeini, J. (2005). The effect of collaborative learning on critical thinking of Iranian EFL learners. Unpublished M.A. thesis Azad University, Central Tehran Branch, Tehran, Iran.

[22] Naunan. D. (1999). Second language teaching and learning. Boston: Heinle \& Heinle.

[23] Paul, R. \& Elder, L. (1997). A brief history of idea of critical thinking. Retrieved June, 2006, from http://www.criticalthinking.org/aboutCT/briefhistoryCT.cfm.

[24] Paul, R. (2004). The state of critical thinking today: the need for substantive concept of critical thinking, Retrieved July 15, 2009 from www.criticalthinking.org.

[25] Tama .C. (1989). Critical Thinking: Promoting it in the The Classroom. Retrieved January, 2004 from http://www.eric. Indiana.edu/ico/digests/d4html.

Mohammad Taghi Hassani assistant professor in TEFL in Imam Hossein University, Tehran and Islamic Azad University, Takestan Branch, Iran. His research interests are EFL writing, psycholinguistics, phonetics, contrastive analysis, English for Specific Purposes, and language teaching methodology.

He has published several articles in language teaching and learning e.g. The effect of Self Assessment on Iranian EFL learners' writing skill published by Iranian EFL Journal in October 2012.

Ramin Rahmany, assistant professor in TEFL in Azad University of Takestan, Iran. His major interests are language and acquisition, computer assisted language learning, and psycholinguistics. He has taught several courses at university like Lan guage methodology and discourse analysis.

$\mathrm{He}$ has published several articles in language learning acquisitions e.g. Acquisition of English Relative Clauses by Persian EFL Learners published by Journal of Language and Linguistic Studies in October 2009.

Mohammad Babaei received his BA in 2000 from Dehkhoda University in Ghazvin and MA in 2013 in TEFL from the Department of English Language at Islamic Azad University of Takestan. He has been teaching English in high schools and Engli sh language institutes in Abhar, Iran for twenty years. 